\title{
The Use of Intuition in the Sponsorship Decision-Making Process
}

\author{
Deborah Delaney \\ Griffith University \\ E-Mail: d.delaney@griffith.edu.au \\ Chris Guidling \\ Griffith University \\ E-Mail: c.guidling@griffith.edu.au \\ Lisa McManus \\ Griffith University \\ E-Mail: l.mcmanus@griffith.edu.au
}

\begin{abstract}
This study examines the use of intuition in sponsorship decision-making and seeks to identify factors affecting intuition's use in the process. Findings support the view that intuition plays an important role in sponsorship decision-making. Support is also provided for the expectation that sponsorship decision-making in large organisations with more formalised decision-making processes is less intuitively based. Furthermore, organisations that place high importance on a trusting relationship when entering into a sponsorship arrangement use relatively high levels of intuition. An association was also found between three aspects of risk exposure and the use of intuition in sponsorship decision-making.

This study advances our understanding of the nature of the role of intuition in sponsorship decision-making. The importance of intuition in sponsorship decisionmaking has been examined in the investment decision-making literature but not the sponsorship literature, and with recent calls for greater use of formalised analytical procedures in sponsorship decision-making, it appears there is considerable potential for decision-makers in the sponsorship area to draw on points of focus raised in this study.
\end{abstract}

Keywords: Sponsorship Decision-Making, Intuition, Investment Decision-Making, Marketing Strategy, Trust, Risk 


\section{INTRODUCTION}

It is well accepted that sponsorship represents an important and unique component of an organisation's integrated marketing strategy (Cornwell, 1995; Masterman, 2007; Meenaghan, 1991; Pope, 1998; Sandler \& Shani, 1993; Shank, 2005). This study seeks to extend our appreciation of the nature of sponsorship management by examining the importance of intuition in the sponsorship decision-making process and to explore for antecedent factors affecting intuition's use in this context.

It would appear reasonable to expect that increasing levels of sponsorship activity would result in greater deployment of structured and formalised sponsorship decisionmaking approaches. Such approaches might include a quantitative analysis such as the demonstration that a proposed sponsorship outlay will surpass a required rate of return threshold. Stewart (2006) promotes the view that marketers should justify their actions and resource allocation decisions in a similar manner to managers in other parts of an organisation. Within the marketing literature, studies concerned with sponsorship have increasingly recognised the need for accountability and demonstration of achieving a satisfactory return on investment (Kuzma, Shanklin \& McCally, 1993; Pope \& Voges, 2000; Stotlar, 2001, 2004; Sweet, 2002). Yet we need to recognise that the 'soft' nature of sponsorship cash flow benefit projections, which is particularly apparent when we recognise that the primary benefits of sponsorship frequently relate to intangibles such as enhanced company image, are likely to defy the rigorous application of conventional return on investment algorithms. This view underscores the likely continuation of an important role for intuition in sponsorship decision-making.

A number of researchers have proposed methods for justifying sponsorship decisions (Copeland, Frisby \& McCarville, 1996; Irwin \& Asimakopoulos, 1992; Masterman \& Wood, 2006; Pitts \& Stotlar, 2007; Pope, 1996; Schoch, 1994; Thwaites \& Carruthers, 1998) and note that sponsors require a decision-making model that can provide guidance for sponsorship choices to substantiate "gut feel" approaches (Armstrong, 1988; Guilding, 2003; Kohl \& Otker, 1985; Kraak \& Olivier, 1997). These commentaries have been somewhat silent or under-specified however, with respect to the exact operationalisation of algorithms that can substantiate decisions based on intuitive feel. Given calls for greater accountability and formalisation in sponsorship decision-making processes, it appears pertinent to shed light on the relative deployment of what can be viewed as the antithesis of these constructs in sponsorship decisionmaking, i.e., intuition.

This empirical study reported herein pursues two primary objectives. First, we investigate the extent to which intuition plays a role in the sponsorship decision-making process. Second, we investigate for antecedent factors associated with greater exercise 
of intuition in sponsorship decision-making. If we conceive of sponsorship decision as an investment, it appears pertinent to note the literature suggesting that organisations that are small or less formalised employ a relatively high degree of intuition in investment decision-making (Chenhall, 2003; Guilding, 2003). Further, prior organisational research suggests that those organisations that emphasise trust in conducting their external alliance relationships tend to employ more intuitive approaches to decision-making with external partners (Das \& Teng, 1998).

The remainder of the paper is organised as follows. The next section provides theoretical context for the study by drawing on prior literature to develop hypotheses concerned with factors affecting the use of intuition in the sponsorship decision-making process. The research method will then be outlined, followed by a presentation of the study's findings. The paper concludes with a discussion of the study's implications, limitations and a suggestion of ways upon which the study can be built in further research.

\section{LITERATURE REVIEW}

Organisational decision-making has been the subject of substantial academic enquiry; this is particularly the case for the subset of decisions that are concerned with an organisational outlay that will stimulate increased cash flows into the future, i.e., investment decisions. The investment decision-making process is a well-studied area of organisational behaviour. The sponsorship investment decision is highly significant as it can involve the allocation of a large financial budget and it can greatly affect a sponsor's external image. Sponsorship decision-making quality can therefore carry far reaching implications for sponsors.

Widely acknowledged formalised models of decision-making are closely associated with the rational decision-making model identified by Koopman and Pool (1991). The rational model requires decision-makers to consider a range of options, compare and evaluate them and select the optimal option (Butler, Davies, Pike \& Sharpe, 1993). Mintzberg, Raisinghani and Theoret (1976) see the decision-making process as involving a number of stages which can be summarised as: the initial recognition of an opportunity, setting of objectives, searching for information, creating solutions, evaluating solutions, choosing the optimal solution, gaining authorisation and implementation. Such standardisation is designed to ensure that actions taken within the organisation are consistent, irrespective of who takes the action (Snell, 1992). This model can be compared to sponsorship selection models promulgated in the literature (Copeland et al., 1996; Irwin \& Asimakopoulos, 1992; Masterman \& Wood, 2006; Pitts \& Stotlar, 2007; Pope, 1996; Schoch, 1994; Thwaites \& Carruthers, 1998). 
Highly distinct from the formalised decision-making approach is the intuitive decision-making model that sees decisions made not on the basis of rational judgement, but intensity of perception. The issue of the effectiveness of judgement or intuition versus rational, analytical procedures has been discussed by researchers for many years. The merit of intuition-based decision-making in organisations has been dismissed by some commentators due to the potential for erroneous, biased or inaccurate decisions (Bonabeau, 2003; Dawes, Faust \& Meehl, 1989; Kahneman, Slovic \& Tversky, 1982; Shoemaker \& Russo, 1993). This view has been challenged in more recent times, however. The increasingly dynamic and fast paced context in which decisions are made has prompted wider acknowledgement of the effectiveness of intuition-based decisionmaking (Dane \& Pratt, 2009; Gigerenzer, 2007; Sadler-Smith, Hodgkinson \& Sinclair, 2008).

In psychology, intuition is referred to as the ability to know valid solutions to problems and decision-making. Intuitive decision-making sees managers making relatively fast decisions without having to compare options. In this decision-making mode, managers can draw on prior related experiences to identify similar situations and intuitively choose preferred solutions (Klein, 2003). Similarly, in strategic decisionmaking, intuition is seen as drawing on accumulated experience. Early in a career a manager can be expected to emphasise explicit analysis, but as expertise is accumulated, some steps in the analysis are dropped and some are carried out subconsciously (Dane \& Pratt, 2007, 2009; Hodgkinson, Langan-Fox \& Sadler-Smith, 2008; Hodgkinson \& Sadler-Smith, 2003; Kahnemann, 2003; Muller \& Ireland, 2005).

Research has shown that managers put greater emphasis on intuition when considering strategic investments in a context characterised by a high degree of uncertainty (Agor, 1986; Butler, et al., 1993; Dane \& Pratt, 2007; Langley, 1990; Van Cauwenbergh, Durinck, Martens, Laveren \& Bogaert, 1996). Agor (1986, p.6) sees intuition as "a product of both factual and feeling cues". Important strategic investment decisions are rarely made on the basis of detailed financial analysis alone; rather they are matters of judgement that draw on past experience and management's vision or beliefs (Butler et al., 1993; Donaldson \& Lorsch, 1983).

Agor (1986) noted that managers use intuition where there is a high degree of risk, analytical data is of little use, there is little precedent, and where there is no obvious preferred solution (p.9). In support of earlier studies by Mares (1991) and Butler et al. (1993), Van Cauwenbergh et al. (1996) found that evaluation of a strategic investment proposal can include the rational dimension, such as formal financial assessment, as well as intuitive judgement. This suggests that while formal analysis is important, information for decision-making often derives from many informal sources and such 
information can affect how a decision solution evolves (Eisenberg, 1984; Issack, 1978; Simons, 1987). There now appears to be a growing consensus of opinion that effective managers will use both intuition and more formalised analysis to make decisions (Simons, 1987; Shapiro \& Spence, 1997; Burke \& Miller, 1999; Hauser, Cushman, Young, Kang-Xing Jin \& Mikhail, 2007).

There has been little empirical research concerned with sponsorship decisionmaking. As it would appear that sponsorship decision-making bears many of the characteristics that are consistent with intuitive approaches to decision-making, it would appear useful to examine the nature of managerial intuition and the factors that affect its use when conceiving of control systems in the sponsorship context.

\section{HYPOTHESES}

Using a theoretical framework that relates the factors of formalisation, trust, risk and size to the use of intuition in the sponsorship decision-making context, six hypotheses have been developed. The motivation for these hypotheses is expounded upon in this section.

\section{Formalisation}

Formalisation can be defined in terms of standardisation of the decision-making process. Organisations that engage in formalised procedures produce standardised systems, have well-defined organisational objectives and behaviour, advocate objective decisions and actions and the formal structure of the organisation is used as a tool to constrain the scope for individual irrationality being exercised (Alkadry \& Nyhan, 2005; Snell, 1992). The literature notes that in connection with decisions that carry strategic implications, there is a tension between formalised decision-making approaches and the exercise of judgement that is influenced by past experience and management's visions or beliefs (Butler et al., 1993; Collier \& Gregory, 1995; Donaldson \& Lorsch, 1983; Guilding, 2003).

In the absence of standardised processes for sponsorship decision-making, there would appear to be considerable scope for intuition impacting the sponsorship decision. This becomes particularly apparent when we compare sponsorship decision-making to the formalisation associated with the annual capital budgeting round in organisations. The extensive research that has been directed to exploring capital budgeting practices has achieved a high degree of consensus concerning the growth in deployment of formalised investment appraisal techniques such as 'Net Present Value' and 'Internal Rate of Return' (see Haka, 2007, for a review). This view is reinforced when it is recognised that many sponsorship investments do not lend themselves to a 
quantification of the benefits deriving from a sponsorship investment decision, such as is required in a formalised process. Following this rationale, we expect that organisations that have less formalised sponsorship decision-making processes afford greater scope to the exercise of intuition when deciding whether to pursue a particular sponsorship opportunity.

Hypothesis 1: Organisations that have a less formalised sponsorship decisionmaking process employ a relatively high degree of intuition in sponsorship decisionmaking.

\section{Trust}

Arnott (2007) comments "trust - a belief in the reliability of a third party, particularly where there is an element of personal risk - lies at the heart of the marketing concept" (p.981). Trust relates to the concept that one party has confidence that a second party will honour their relationship responsibilities and not act in a way that damages the relationship (Doz, 1996; Kanter, 1994; Kumar, 1996; Ring \& Van de Ven, 1992). The presence of trust can be viewed as an important facilitator of an enduring sponsorship arrangement. In most agreements, a level of trust between the two parties is required, as it is impossible to draft a contract that covers all contingencies that can arise when two organisations enter into a sponsorship arrangement (Das \& Teng, 1998). For those relationships where a sponsor has a high degree of trust in a rightsholder ${ }^{1}$, the sponsor can view the trust as underwriting a rightsholder's pledge to provide a quality service to the sponsor. In light of this underwritten facet, the sponsor can be expected to feel a diminished need to expend resources in the maintenance of a highly formalised sponsorship decision-making process. The presence of high trust in a relationship will provide the sponsor with greater confidence that the rightsholder will act in a manner as agreed and expected by the sponsor. Following this rationale, if most of an organisation's sponsoring activities are conducted in the context of high trust relationships, the sponsoring entity will attach diminished importance to sustaining formalised sponsorship decision-making processes. It is expected that where a sponsor experiences a high degree of trust in a rightsholder, the resulting confidence will provide the sponsor with latitude to exercise a relatively high degree of intuition in sponsorship decision-making. Consistent with this rationale, the following hypothesis has been developed.

Hypothesis 2: Organisations that place high importance on trust when entering a sponsorship arrangement employ a relatively high degree of intuition in sponsorship decision-making.

\footnotetext{
${ }^{1}$ In this study, 'rightsholder' is defined as the recipient of sponsorship funding.
} 


\section{Risk}

The corporate finance and agency theory literatures can be drawn upon to inform a conceptualisation of the role of risk in relation to sponsorship decision-making. Business uncertainty refers to volatility of earnings before interest and tax. Central to such uncertainty is the risk that an organisation may not be able to cover its operating costs (Gitman, Juchau \& Flanagan, 2008). Ross, Westerfield and Jordan (2008) define business risk as the risk inherent in a firm's operations. Where an organisation is financed solely by equity, business risk is the only risk shareholders face, however when an organisation supplements its financing through debt funding, it also confronts financial risk. The nature of an organisation's industry contributes much to its business risk as it can be in an industry that is subject to volatile and capricious demand (high risk) or subject to high raw material price volatility (high risk). An organisation has much greater control over its financial risk, however, as this relates to an organisation's financing decision (the greater its debt financing, the greater its financial leverage and risk). It is this capacity to manage financial risk exposure that resulted in this study's inclusion of financial risk as a variable of interest.

A particular dimension of business uncertainty concerns the risk stemming from the agency relationship apparent in any sponsorship arrangement. From an agency theory perspective, it would appear that in a sponsorship relationship where one party (the sponsor) assigns work to another party (the rightsholder), contractual issues can arise, as the rightsholder may have scope to act opportunistically and in a self-interested manner (Berle \& Means, 1962; Eisenhardt, 1989; Jensen \& Meckling, 1976; Lambert, 2001). Any sponsoring entity that perceives a potential for high risk when entering into a sponsorship arrangement would be expected to act in a manner consistent with minimising the potential for unexpected negative outcomes in connection with its relationship with a rightsholder. In addition, the type and form of sponsorship entered into by an organisation carries a risk dimension, as sponsorship activities carry varying degrees of risk. For example, where an organisation sponsors a football team, it is exposing itself to the risk that a player acts in an inappropriate manner that becomes well publicised, with the result that negative imagery is cast upon the team and, by association, the sponsor.

An association between a sponsoring organisation's risk profile and the degree of intuition it employs in its sponsorship decision-making processes is expected. If an organisation is highly risk averse, it might be expected to adopt a highly formalised approach to sponsorship decision-making in an attempt to ensure all risk issues are documented and appraised prior to entering into a sponsorship arrangement. An alternative view with a contrary outcome can also be advanced, however. One could 
argue that there are dimensions of risk that defy formalised assessment and that such dimensions warrant intuitive assessment. These conflicting views on how risk might impact the exercise of intuition in sponsorship decision-making have resulted in the formulation of three non-directional hypotheses. The three hypotheses correspond to three dimensions of risk: organisational financial risk, an organisation's overall risk aversion culture, and perceptions of risk arising from sponsorship activities.

Hypothesis 3: There is an association between organisational financial risk and the degree of intuition employed in sponsorship decision-making.

Hypothesis 4: There is an association between an organisation's risk avoidance culture and the degree of intuition it employs in sponsorship decision-making.

Hypothesis 5: There is an association between perceived risk in sponsorship and the degree of intuition employed in sponsorship decision-making.

\section{Size}

Several studies have noted a positive relationship between size and degree of formalisation in management control systems (Bruns \& Waterhouse, 1975; Chenhall, 2003; Merchant, 1981). Associated with the economies of scale notion, it appears reasonable to expect that larger organisations can more easily justify the expenditure of resources directed to the development of formalised systems. It also appears that, as a function of their size, large organisations will expend larger absolute amounts of funds on sponsorship. This larger sponsorship expenditure can be seen as justifying the development of more formalised sponsorship decision-making systems. Consistent with this, it appears that where an organisation invests a large quantum of funds in sponsorship, irrespective of the size of the organisation, they would tend to see a greater need for a formalised investment decision-making process. The large quantum of sponsorship funds expended would place a greater onus on the development of a formalised decision-making process to ensure that the funds are invested in an optimal manner. Consistent with this rationale, it is expected that there will be a negative association between the size of an organisation and the use of intuition in sponsorship decision-making.

Hypothesis 6: Large organisations employ relatively less intuition in sponsorship decision-making. 


\section{RESEARCH METHOD}

\section{Sampling procedure}

The Australian Sponsorship Management Association (ASMA) membership database was used as the study's sample frame. ${ }^{2}$ All ASMA members were included in the sample, yielding a sample frame of 237. The mail-out to the ASMA membership comprising a covering letter, questionnaire and a return pre-paid self-addressed envelope was undertaken in 2010. A second mail-out was distributed to all members three weeks after the initial mailing. This comprised a follow-up covering letter, questionnaire and a return pre-paid self-addressed envelope. In advance of distributing the questionnaire, ASMA provided details of the survey in their newsletter and emailed its membership to encourage participation in the survey.

Of the initial 237 questionnaire surveys mailed, nine surveys were returned marked "person unknown at this address", and nine were returned with a note indicating they were not the appropriate person to be completing the survey. The response rate was therefore determined using a final sample size of 219. Responses were received from 34 members for the first mail-out and 23 members for the second mail-out. The final sample size of 57 represents a response rate of 26\%. This response is comparable to response rates typically achieved in organisational research (McBurney, 1994), although it should be noted that a higher response rate would have elevated the reliability of the study's reported findings.

A profile of the respondents is presented in Table 1 . The majority of the respondents held the position of Sponsorship Manager or Marketing Manager (54.4\% and $21.1 \%$, respectively). The three main industries represented in the sample were the Finance/Banking/Insurance, Sport, and Professional Services industries (22.8\%, 14\% and $10.5 \%$, respectively).

Due to ASMA's privacy protocol, the investigation for non-response bias was undertaken by an ASMA official. The most widely cited reasons for non-response were "too busy" and "the wrong person was asked to complete the survey". No reason cited gave rise to a concern for non-response bias. Non-parametric Mann-Whitney $U$ tests were also performed to investigate for any difference between early and late respondents. This was undertaken by comparing responses provided by first mail-out respondents to the responses of second mail-out respondents. No significant differences between early and late respondents for any of the questionnaire items were noted.

\footnotetext{
2 "A pilot study involving a review of the questionnaire by seven academics and five sponsorship practitioners was conducted in order to promote the survey questionnaire's relevancy, reliability, validity and to minimise ambiguity”.
} 
Table 1 Characteristics of the Sample Respondents

\begin{tabular}{|c|c|c|}
\hline Position Title: & Frequency & $\begin{array}{c}\text { Percentage } \\
\%\end{array}$ \\
\hline Sponsorship Manager & 31 & 54.4 \\
\hline Marketing Manager & 12 & 21.1 \\
\hline CEO & 3 & 5.3 \\
\hline Business Development Manager & 3 & 5.3 \\
\hline Community Manager & 2 & 3.5 \\
\hline Director of Publicity & 2 & 3.5 \\
\hline Public Affairs Officer & 2 & 3.5 \\
\hline Director & 1 & 1.7 \\
\hline Partnerships Manager & $\underline{1}$ & $\underline{1.7}$ \\
\hline Total: & $\underline{57}$ & $\underline{100}$ \\
\hline Industry: & Frequency & $\begin{array}{c}\text { Percentage } \\
\%\end{array}$ \\
\hline Finance/Banking/Insurance & 13 & 22.8 \\
\hline Sport & 8 & 14.0 \\
\hline Professional Services & 6 & 10.5 \\
\hline Government & 5 & 8.8 \\
\hline Manufacturing & 4 & 7.0 \\
\hline Communications & 3 & 5.3 \\
\hline Retail & 3 & 5.3 \\
\hline Utility & 3 & 5.3 \\
\hline Arts & 2 & 3.5 \\
\hline Tourism & 2 & 3.5 \\
\hline Other & $\underline{8}$ & $\underline{14}$ \\
\hline Total: & $\underline{57}$ & $\underline{100}$ \\
\hline Years Employed in Current Position: & Frequency & $\begin{array}{c}\text { Percentage } \\
\%\end{array}$ \\
\hline $0-5$ years & 37 & 64.9 \\
\hline $6-10$ years & 15 & 26.4 \\
\hline $11-15$ years & 4 & 7.0 \\
\hline 31-35 years & $\underline{1}$ & $\underline{1.7}$ \\
\hline Total: & $\underline{57}$ & $\underline{100}$ \\
\hline
\end{tabular}

$n=57$

\section{VARIABLE MEASUREMENT}

\section{Intuition Used in Sponsorship Decision-Making}

The dependent variable, the degree of intuition used in sponsorship decisionmaking, was measured using six items derived from Van Cauwenburgh et al.'s (1996) examination of strategic investment decision processes. On a seven-point scale, respondents were asked to indicate their extent of agreement with three statements relating to managers' use of an intuitive approach in sponsorship decision-making and 
three statements relating to their organisation's use of intuitively oriented approaches in sponsorship decision-making (Int1 - Int6: presented as first panel in Appendix A).

Table 2 presents descriptive statistics pertaining to the six questionnaire items used to gauge the degree to which an intuitive approach is used in the sponsorship decisionmaking process. The table reveals scores close to the mid-point, with three items yielding means above the mid-point and three items yielding scores below the mid-point of the range. The clustering of the mean scores around the mid-point of the six measurement scales suggests intuition is employed to a fair degree in sponsorship decision-making.

Table 2 Descriptive Statistics of Intuition Items

\begin{tabular}{lcccccc}
\hline Descriptives & Int1 & Int2 & Int3 & Int4 & Int5 & Int6 \\
\hline Mean & 4.88 & 4.33 & 3.72 & 4.82 & 3.37 & 3.93 \\
Median & 5 & 5 & 3 & 5 & 3 & 4 \\
Standard Deviation & 1.42 & 1.54 & 1.46 & 1.44 & 1.46 & 1.41 \\
Minimum & 2 & 2 & 1 & 2 & 1 & 1 \\
Maximum & 7 & 7 & 7 & 7 & 7 & 7 \\
\hline
\end{tabular}

A principal components analysis of these six items revealed two factors with eigenvalues greater than one (total explained variance of 70.57\%). Factor 1 (eigenvalue $=2.505$ ) had an explained variance of $41.75 \%$ and item factor loadings of $0.720,0.755$, 0.863, 0.798 for the following four items: 'the manager who oversees most sponsorship decisions prefers to take an intuitive approach rather than a numbers based approach to justifying a decision to sponsor'; 'in my organisation, sponsorship proposals are accepted if, on face value, they appear to make sound commercial sense'; 'we will tend to go with a sponsorship proposal if it gives us a good 'gut feel'; and 'the sponsorship decision-making process is quite intuitive'. The Cronbach alpha for these four items is 0.803. Nunnaly (1978) suggests that a Cronbach alpha in excess of 0.70 represents a satisfactory reliability index. In light of this dominant factor, the degree of intuition in sponsorship decision-making was measured using the average of these four items. The second factor comprised two items yielding a correlation coefficient of $0.618(p<0.01)$ and a total variance explained of $28.81 \%$. As only two items were loaded on this factor, it was viewed as insufficiently robust to warrant further analysis in the study (Tabachnick \& Fidell, 2007). 


\section{Formalisation of Sponsorship Decision-Making Process}

Degree of formalisation of the sponsorship decision-making process was ascertained by posing six questions (Form1 - Form6: presented as second panel in Appendix A). These questions represent adaptations of questions used by Lamminmaki, Guilding and Pike (1996) in their study of capital budgeting and Kraus, Harms and Schwarz (2006) who measured formalisation in terms of written planning, informal planning or no planning, and also scales developed by Olson, Slater and Hult (2005). The measures were also informed by the research of Walker and Ruekert (1987) who examined degree of formalisation in relation to the use of standard operating procedures and the use of a policy manual for decision-making, as well as the work of Alkadry and Nyhan (2005) that operationalised formalisation in terms of rules, adherence to policy and the use of documented criteria for making decisions.

The descriptive statistics shown in Table 3 indicate that a formalised approach is widely used in the sponsorship decision-making process. Mean scores for the six items range from 4.86 to 5.58 and are all well above the mid-point of the measures' ranges. These observations suggest a high degree of formalisation in the sponsorship decisionmaking process.

Table 3 Descriptive Statistics of Formalisation Items

\begin{tabular}{lcccccc}
\hline Descriptives & Form1 & Form2 & Form3 & Form4 & Form5 & Form6 \\
\hline Mean & 5.58 & 5.32 & 5.16 & 4.98 & 4.86 & 4.86 \\
Median & 6 & 5 & 5 & 5 & 5 & 5 \\
Standard Deviation & 1.30 & 1.52 & 1.41 & 1.69 & 1.59 & 1.58 \\
Minimum & 1 & 2 & 2 & 2 & 2 & 2 \\
Maximum & 7 & 7 & 7 & 6 & 7 & 7 \\
\hline
\end{tabular}

A principal components analysis of the six formalisation items was conducted. This yielded a single factor with an eigenvalue greater than one (4.155) and an explained variance of $69.25 \%$, and item factor loadings of $0.753,0.905,0.873,0.814$, 0.695, and 0.928, respectively. The six items have a Cronbach alpha of 0.907, suggesting a high degree of uni-dimensionality and that the construct has high reliability (Nunnaly, 1978). In light of this single factor result, the average of the six items has been used as the measure of sponsorship decision process formalisation.

\section{Importance of Trust in Sponsorship Relationship}

Trust was measured using questions deriving from Zaheer and Venkatraman's (1995) study of the role of trust in economic exchange. Zaheer and Venkatraman 
developed three items that focussed on "high level of mutual trust", "well-known for fair dealing" and "stands by its word" to measure trust. The adapted questions employed for this study are presented as the final panel in Appendix A.

A principal components analysis of these three items was undertaken and yielded one factor with an eigenvalue greater than one (1.944). This factor had an explained variance of $64.80 \%$ and item factor loadings of $0.732,0.822$, and 0.856 . Cronbach alpha for these three items was 0.720, suggesting uni-dimensionality of the construct (Nunnaly, 1978). Accordingly, importance of trust in entering into a sponsor arrangement was measured as the average of these three items.

\section{Risk}

Three risk related constructs were measured: financial risk, sponsorship investment risk and organisational risk aversion. Financial risk was measured as the debt level of the sponsor's organisation. Respondents were asked to indicate on a seven point scale ranging from ' 1 ' (strongly disagree) to ' 7 ' (strongly agree), the extent to which they agreed with the statement "for its size, my organisation has a high debt level". Two items were designed to assess the respondent's perception of sponsorship investment risk. On a seven point scale ranging from ' 1 ' (strongly disagree) to '7' (strongly agree), respondents were asked to indicate the extent to which they agreed with the following statements: 'given the nature of the business and market, sponsorship can be risky'; and 'sponsorships entered into can have negative consequences'. As these two items were highly significantly correlated ( $p<0.01$ ), the average of the two items was calculated and used in the subsequent analysis as the measure of perceived risk in sponsorship.

As organisational risk aversion can be viewed as a relative characteristic, a comparative rating scale that included the phrase 'relative to' was used to measure this construct. On a seven-point Likert scale ranging from ' 1 ' (seeks to avoid risk) to '7' (copes well with risk), respondents were asked to provide a response to the question: 'relative to its competitors, does your organisation have a culture that seeks to avoid risk?’

\section{Size}

Previous studies have measured size from a range of perspectives including total assets, total sales, total revenue and number of employees. In this study, respondents were asked to indicate their total revenue, their total sponsorship budget and relative to similar organisations, the total amount that they expended on sponsorship activities on a seven-point scale ranging from ' 1 ' (much less) to '7' (much more). 
Due to the large number of missing values for both total revenue and total sponsorship budget, size has been measured as the amount spent on sponsorship activities relative to similar organisations.

\section{Findings}

Table 4 presents the descriptive statistics and the Spearman's rank correlation coefficients for the variables under examination. There are a number of statistically significant relationships between the variables, particularly between the dependent variable ('intuition') and the independent variables. The statistically significant correlations between degree of intuition and formalisation, financial risk, risk culture, sponsorship risk and size suggest linear relationships. While the lower panel of Table 4 highlights three significant correlations between independent variables, the VIF indices presented in Table 5 suggest that multicollinearity does not represent a significant threat to the robustness of the regression analysis undertaken. ${ }^{3}$

Table 4 Descriptive Statistics and Correlations of Variables in the Study

\begin{tabular}{lcccccc}
\hline Variable & $\begin{array}{c}\text { Theoretical } \\
\text { Range }\end{array}$ & Actual Range & Mean & $\begin{array}{c}\text { Standard } \\
\text { Deviation }\end{array}$ & Skewness & Kurtosis \\
\hline Intuition & $1-7$ & $2-6$ & 3.96 & 1.14 & 0.13 & -0.73 \\
Formalisation & $1-7$ & $2.3-7$ & 5.11 & 1.26 & -0.27 & -0.76 \\
Trust & $1-7$ & $1.3-7$ & 5.08 & 1.24 & -0.49 & 0.07 \\
Financial Risk & $1-7$ & $1-7$ & 2.96 & 1.68 & 0.41 & -0.85 \\
Risk Culture & $1-7$ & $1-7$ & 3.30 & 1.99 & 0.40 & -1.21 \\
Sponsorship Risk & $1-7$ & $1-6.5$ & 3.48 & 1.36 & 0.17 & -0.39 \\
Size & $1-7$ & $1-7$ & 3.65 & 1.46 & -0.01 & -0.26 \\
\hline Correlations: & Intuition & Formalisation & Trust & Financial & Risk & Sponsorship \\
& & & & Risk & Culture & Risk \\
\hline Intuition & 1.00 & & & & & \\
Formalisation & $-0.28^{* *}$ & 1.00 & & & & \\
Trust & 0.18 & 0.01 & 1.00 & & & \\
Financial Risk & $0.34^{* *}$ & -0.08 & 0.07 & 1.00 & & \\
Risk Culture & $0.46^{* *}$ & -0.17 & 0.05 & 0.03 & 1.00 & \\
Sponsorship Risk & $0.40^{* *}$ & $-0.26^{*}$ & -0.11 & $0.44^{* *}$ & 0.08 & 1.00 \\
Size & $0.24^{*}$ & 0.07 & -0.11 & -0.12 & $0.22^{*}$ & 0.11 \\
\hline$n=57{ }^{*} p<0.05 ;{ }^{* *}$ & $p<0.01$ & & & & & \\
& & & & & &
\end{tabular}

The data was screened for the existence of any influential observations through the examination of residuals, calculation of leverage points, Mahalanobis distance and Cook's distance. No outlying influential observations were identified.

\footnotetext{
${ }^{3}$ The VIF values presented in Table 5 are well below the generally accepted critical threshold value of 10 (Hair et al., 2006).
} 
Multiple regression analysis was conducted to test the research hypotheses. While the size of the sample is not large, it is considered sufficient for application of multiple regression analysis, as the sample exceeds the requisite number of cases noted by Tabachnick and Fidell (2007).

The research hypotheses were tested by fitting the variables to the following equation:

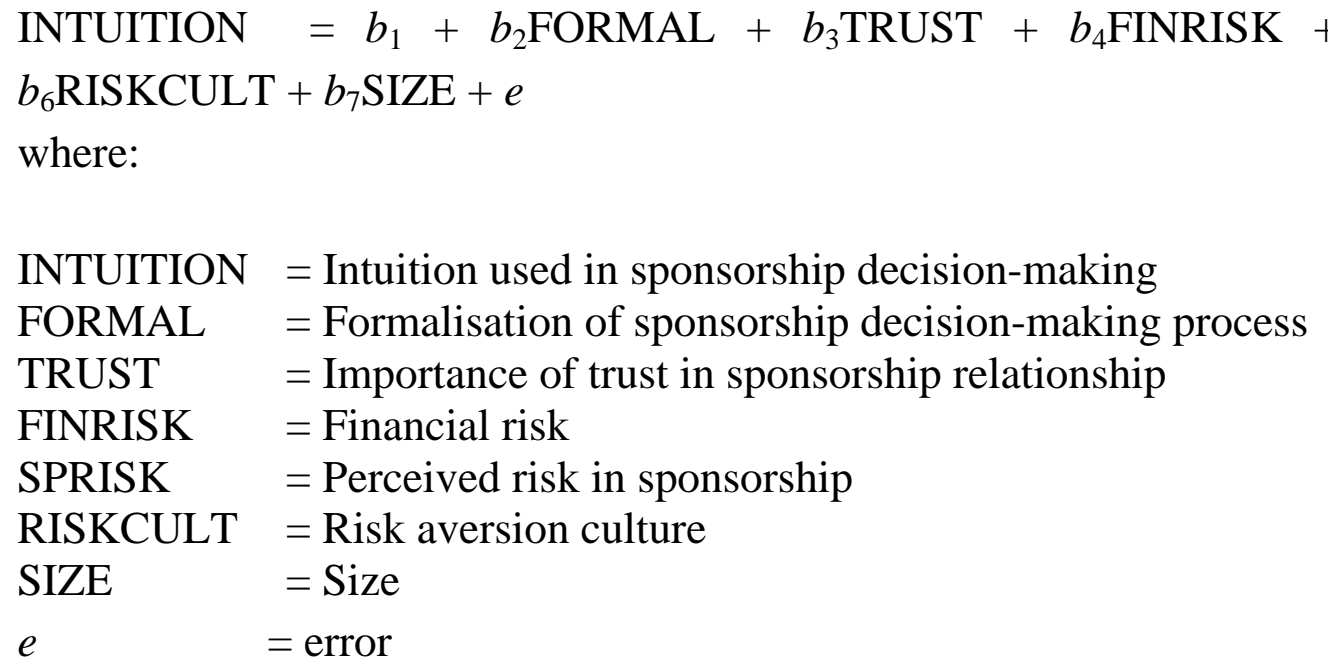

Table 5 Intuition in Sponsorship Decision-making Process Regression Analysis Results

\begin{tabular}{lccccc}
\hline & $\begin{array}{c}\text { Expected } \\
\text { Sign }\end{array}$ & Hypothesis & $\begin{array}{c}\text { Standardised } \\
\text { Regression } \\
\text { Coefficients }\end{array}$ & t-value ${ }^{\mathrm{a}}$ & VIF \\
\hline Constant & - & H1 & -0.15 & $-1.35^{*}$ & 1.13 \\
Formalisation & + & H2 & 0.20 & $1.84^{* *}$ & 1.04 \\
Trust & $?$ & H3 & 0.23 & $1.89^{* *}$ & 1.32 \\
Financial Risk & $?$ & H4 & 0.36 & $3.26^{* * *}$ & 1.09 \\
Risk Culture & $?$ & H5 & 0.23 & $1.89^{* *}$ & 1.42 \\
Sponsorship Risk & - & H6 & 0.19 & $1.73^{* *}$ & 1.14 \\
Size & - & & &
\end{tabular}

$\begin{array}{ll}\text { Adjusted } R^{2} & 0.391 \\ F & 7.001 \\ \text { Significance } & 0.000\end{array}$

\footnotetext{
${ }^{a}$ All $t$-tests are one-tailed tests of significance, for those independent variables with a directional relationship with the dependent variable that is consistent with the formulated propositions.

${ }^{b}$ Regression coefficient is significantly positive, i.e., $p<0.05$ in the opposite direction as that hypothesised.

$* * * p<0.01 ; * * p<0.05 ; * p<0.10$
} 
Results of the regression analysis are presented in Table 5 . The multiple regression equation is statistically significant $\left(p<0.001\right.$ ) with an adjusted $R^{2}$ of $39.1 \%$. Moderate support is shown for Hypothesis 1 ( $p<0.10$ ); less formalised sponsorship decisionmaking processes are positively related to the exercise of intuition in sponsorship decision-making. Support is also provided for Hypothesis 2, suggesting that organisations that attach high importance to developing trusting sponsorship relationships exercise a high degree of intuition in sponsorship decision-making ( $p<$ 0.05). Support is also provided for Hypotheses 3, 4 and 5 that focus on distinct dimensions of risk and the implications for use of intuition in sponsorship decisionmaking. There is a statistically significant positive relationship between the degree of intuition used in sponsorship decision-making and financial risk $(\mathrm{p}<0.01)$, perceived risk in sponsorship $(\mathrm{p}<0.05)$ and an organisational risk avoidance culture $(p<0.05)$. No support has been found, however, for Hypothesis 6 which posited a negative relationship between organisational size and intuition used in sponsorship decisionmaking. In fact, contrary to the hypothesised relationship, the model yields a significant positive relationship between the two variables, suggesting that larger organisations deploy more intuition in sponsorship decision-making $(p<0.05)$. As it is hard to conceive of any convincing rationale for this observed relationship, it is felt this observed relationship is little more than a statistical artefact of the data collected.

\section{DISCUSSION AND CONCLUSION}

This study advances our understanding of sponsorship decision-making, and in particular the role of intuition in sponsorship decision-making. A particular academic contribution of this study concerns the attention it has directed to the way sponsorship decisions are made. Although sponsorship can be conceived of as an investment (i.e. an outlay of funds that will generate future benefits), sponsorship decision-making has received very little research attention compared to the research attention quantum directed to more generic investment decision-making in organisations (Haka, 2007). It is hoped that insights provided by this work can stimulate further research directed to developing a stronger understanding of the nature of sponsorship decision-making.

Two research objectives have been pursued: (1) to appraise the extent that intuition is used in sponsorship decision-making and (2) to identify factors affecting the use of intuition in sponsorship decision-making. The motivation for examining the importance of intuition in sponsorship decision-making stemmed from the fact that this decisionmaking orientation has been examined in the investment decision-making literature (Butler et al., 1993; Van Cauwenbergh et al., 1996; Guilding, 2003) but not the sponsorship literature, and also the fact that there have been calls for greater use of 
formalised analytical procedures in sponsorship decision-making (Kohl \& Otker, 1985; Armstrong, 1988; Kraak \& Olivier, 1997; Clark, 2000; Clark, Abela \& Ambler, 2006). As the exercise of intuition can be seen as the antithesis of formalised analytical procedures, the study can be viewed as shedding an inverse light on the use of formalised analytical procedures, as high use of intuition would, by implication, suggest low use of formalised analytical procedures.

The study has uncovered a moderate degree of intuition exercised in the sponsorship decision-making process. This claim is based on the six items designed to measure the exercise of intuition yielding means that cluster around the mid-point of the measurement range. It is notable, however, that the mean scores for the degree of formalisation in sponsorship decision-making scored consistently higher, suggesting that sponsorship decision-making can be viewed as more formalised than intuitive. The evidence uncovered in this study can be seen as supporting a view that those suggesting that marketers must relate their proposals to the value of the firm and therefore prepare their proposals in financial terms (e.g., Sidhu \& Roberts, 2008) is starting to have an effect on the conduct of sponsorship decision-making. It should not be forgotten, however, that the presence of standard deviations in the data collected underscore the fact that some (albeit a minority) of the organisations may well have a sponsorship decision-making orientation that is more intuitive than formalised. As prior research has shown that management increasingly base their decisions on intuitive approaches in the presence of higher degrees of uncertainty (Agor, 1986; Butler et al., 1993; Langley, 1990; Van Cauwenbergh et al., 1996; Hauser, Cushman, Young et al., 2007; Dane \& Pratt, 2007, 2009), it would appear likely that those organisations that employ more of an intuitive orientation in sponsorship decision-making are likely to be making sponsorship decisions where the nature of the benefits are difficult to operationalise or are uncertain.

Given the limited prior empirical research attention directed to the role of intuition in marketing decision-making, it appears that a significant academic contribution of this study concerns the manner in which it has highlighted the relative importance of intuitive decision-making in sponsorship decision-making. Similar to sponsorship, some forms of advertising can be more concerned with building long term brand image than the stimulation of increased sales over the short term. This signifies a key parallel between sponsorship and advertising, as they both can be focused on building an intangible asset that does not lend itself readily to monetary measurement. On a priori grounds, this leads us to expect there is a high propensity for an intuitive decisionmaking style to be manifested in advertising budget determination. This expectation appears worthy of specific research examination. 
With respect to the study's second objective concerning the determination of factors that affect the use of intuition in sponsorship decision-making, as reported in the preceding section, statistically significant support has been provided for all hypotheses advanced, with the exception of the hypothesis concerning an expectation that large organisations place less emphasis on the exercise of intuition in sponsorship decisionmaking.

The finding concerning a significant antecedent role for trust in sponsorship decision-making style represents a contribution to the large body of literature concerned with the importance of trust between organisations. This finding carries resonance with the position of Blau (1964), Fox (1974), Broadbent, Dietrich and Laughlin (1996) and is supportive of Neu (1991) who comments that "when high levels of trust exist, there is no need for a contract..." (p.247). The importance of trust has also been highlighted in recent marketing and management research (Fang, Palmatier, Scheer \& Li, 2008; Palmatier, Dant, and Grewel, 2007; Zaheer, McEvily \& Perrone, 1998). This study's findings, considered in the context of the literature on trust, highlights the importance of conducting further examination of the importance and role of trust in future research concerned with sponsorship decision-making.

The study's finding of a significant relationship between the use of intuition in sponsorship decision-making and the three dimensions of risk that have been examined, appears as notable, particularly due to the limited prior attention directed to risk in the context of sponsorship decision-making. Risk is a construct that has been extensively examined in the finance literature, due to its inextricable linkage to much finance theory. The findings of this study provide due cause to suggest it is a construct that could also play an informative role in organisational studies concerned with the nature of marketing decision-making. Due to the relative novelty of the context in which risk has been examined in the current study, it would appear that verification of the study's findings and also further examination of the role that risk might play in other marketing decision-making contexts are to be welcomed. Although an association between the risk dimensions examined and intuitive sponsorship decision-making had been expected, the lack of a pertinent prior literature precluded the reasonable development of directional hypotheses. The protracted world-wide economic recession subsisting around the time the study was conducted underscores the extent to which financial risk is a pertinent factor that can impact organisational decision-making. Where a risk avoidance organisational culture exists, it appears reasonable to expect an organisation to use a high degree of intuition as part of a strategy directed to appraising the riskiness of a particular organisational decision, such as entering into a sponsorship arrangement. Recent commentary on risk provided by Miller, Kurunmaki and O’Leary (2008) 
explores risk management in terms of managing risk by developing the means to "have a set of risks or technologies that allow one to intervene in the name of risk" (p.943). Future research on sponsorship decision-making could review risk management mechanisms in order to further our understanding of how organisations manage risk, using tools such as risk committees, risk maps and assurance frameworks.

Our results should be interpreted in light of the normal shortcomings of social scientific research. It should be noted that the questionnaire survey was sent to members of the only sponsorship management organisation in Australia. Although this database appears to contain a reasonable cross-section of different types of organisations with a range of sizes, it is impossible to determine whether this membership is indicative of the population of organisations engaged in sponsoring in Australia. The analysis was undertaken using a limited sample size, and although the sample appears sufficiently large to enable the type of analysis undertaken, a larger sample size would have added to the reliability of the findings presented. It should also be noted that due to a lack of prior related studies, risk has been measured using untried measures. Every effort was made to ensure that the measures used were valid, however further research may be able to provide further advances on the measures adopted for this study.

\section{REFERENCES}

Agor, W. (1986). The logic of intuition: How top executives make important decisions.

Organizational Dynamics, 14, 5-18. http://dx.doi.org/10.1016/00902616(86)90028-8

Alkadry, M.G., \& Nyhan, R C. (2005). The impact of rational organizations on public administrators: A structural equation model. International Journal of Organization Theory and Behavior, 8, 155-173.

Armstrong, C. (1988). Sports sponsorship: A case study approach to measuring effectiveness. European Research, May, 97-103.

Arnott, D.C. (2007). Trust - current thinking and future research. European Journal of Marketing, 41, 981-987. http://dx.doi.org/10.1108/03090560710773291

Berle, A.A., \& Means, G.C. (1962). The Modern Corporation and Private Property. New York: Macmillan.

Blau, P. (1964). Exchange and Power in Social Life. New York: Wiley \& Sons.

Bonabeau, E. (2003). Don’t trust your gut. Harvard Business Review, 81,116-123.

Broadbent, J., Dietrich, M., \& Laughlin, R.C. (1996). The development of principalagent, contracting and accountability relationships in the public sector: Conceptual 
and cultural problems. Critical Perspectives on Accounting, 7, 259-284. http://dx.doi.org/10.1006/cpac.1996.0033

Bruns Jr., W.J., \& Waterhouse, J.H. (1975). Budgetary control and organizational structure. Journal of Accounting Research, Autumn, 177-203.

Burke, L.A., \& Miller, M.K. (1999). Taking the mystery out of the intuitive decision making. Academy of Management Executive, 13, 91-99. http://dx.doi.org/10.5465/AME.1999.2570557

Butler, R., Davies, L., Pike, R., \& Sharp, J. (1993). Strategic investment decisions: Theory practice and process. London: Routledge.

Chenhall, R. (2003). Management control systems design within its organizational context: Findings from contingency-based research and directions for the future. Accounting, Organizations and Society, 28,127-168. http://dx.doi.org/10.1016/S0361-3682(01)00027-7

Clark, B.H. (2000). Managerial perceptions of marketing performance: Efficiency, adaptability, effectiveness and satisfaction. Journal of Strategic Marketing, 8, 3-25. http://dx.doi.org/10.1080/096525400346286

Clark, B.H., Abela, A.V., \& Ambler, T. (2006). Behind the wheel. Marketing Management, 15, (3), 18-23.

Collier, P., \& Gregory, A. (1995). Investment appraisal in service industries: a field study analysis of the U.K. hotels sector. Management Accounting Research, 6, 3357.

Copeland, R., Frisby, W., \& McCarville, R. (1996). Understanding the sports sponsorship process from a corporate perspective. Journal of Sports Management, 10, 32-48.

Cornwell, T.B. (1995). Sponsorship-linked marketing development. Sports Marketing Quarterly, 4, 13-24.

Dane, E., \& Pratt, M. (2007). Exploring intuition and its role in managerial decision making. Academy of Management Review, 32, 33-54. http://dx.doi.org/10.5465/AMR.2007.23463682

Dane, E., \& Pratt, M. (2009). Conceptualizing and measuring intuition: A review of recent trends. International Review of Industrial and Organizational Psychology, 24, 1-40. http://dx.doi.org/10.1002/9780470745267.ch1

Das, T.K., \& Teng, B. (1998). Between trust and control: Developing confidence in partner cooperation in alliances. Academy of Management Review, 23, 491-512. http://dx.doi.org/10.2307/259291

Dawes, R.M., Faust, D., \& Meehl, P.E. (1989). Clinical versus actuarial judgment. Science, 31, 1668-1674. http://dx.doi.org/10.1126/science.2648573 
Donaldson, G., \& Lorsch, J. (1983). Decision making at the top. New York: Basic Books.

Doz, Y.L. (1996). The evaluation of cooperation in strategic alliances: Initial conditions or learning processes. Strategic Management Journal, 17, 55-83.

Eisenberg, D.J. (1984). How senior managers thinks. Harvard Business Review, 62, 8090.

Eisenhardt, K.M. (1989). Making fast strategic decisions in high-velocity environments. Academy of Management Journal, 32, 543-576. http://dx.doi.org/10.2307/256434

Fang, E., Palmatier, R.W., Scheer, L., \& Li, N. (2008). Trust at different organizational levels. Journal of Marketing, 72, 80-98. http://dx.doi.org/10.1509/jmkg.72.2.80

Fox, A. (1974). Beyond contract: Work, power and trust relations. London: Faber and Faber.

Gitman, L., Juchau, R., \& Flanagan, J. (2008). Principles of managerial finance (8th ed.). French's Forest, NSW: Pearson Education.

Gigerenzer,G. (2007). Gut feelings: The intelligence of the unconscious. New York: Viking.

Guilding, C. (2003). Hotel owner/operator structures: Implications for the capital budgeting process. Management Accounting Research, 14, 179-199. http://dx.doi.org/10.1016/S1044-5005(03)00049-0

Haka, S.F. (2007). A review of the literature on capital budgeting and investment appraisal: Past, present, and future musings. In C. Chapman, A. G. Hopwood \& M. D. Shields (Eds.), Handbook of Management Accounting Research, 2, 697-728. New York: Elsevier. http://dx.doi.org/10.1016/S1751-3243(06)02010-4

Hauser, M., Cushman, F., Young, L., Kang-Xing Jin, R., \& Mikhail, J. (2007). A dissociation between moral judgments and justifications. Mind and Language, 22, 1-21. http://dx.doi.org/10.1111/j.1468-0017.2006.00297.x

Hodgkinson, G.P., Langan-Fox, J., \& Sadler-Smith, E. (2008). Intuition: A fundamental bridging construct in the behavioural sciences. British Journal of Psychology, 99, 1-27. http://dx.doi.org/10.1348/000712607X216666

Hodgkinson, G.P., \& Sadler-Smith, E. (2003). Complex or unitary? A critique and empirical re-assessment of the Allinson-Hayes Cognitive Style Index. Journal of Occupational and Organizational Psychology, 76, 243-268. http://dx.doi.org/10.1348/096317903765913722

Irwin, R.L., \& Asimakopoulos, M.K. (1992). An approach to the evaluation and selection of sport sponsorship proposals. Sport Marketing Quarterly, 1, 43-51.

Issack, T F. (1978). Intuition: An ignored dimension in management. Academy of Management Review, 3, 917-922. http://dx.doi.org/10.2307/257948 
Jensen, M.C., \& Meckling, W.H. (1976). Theory of the firm: Managerial behavior, agency costs, and ownership structure. Journal of Financial Economics, 3, 305360. http://dx.doi.org/10.1016/0304-405X(76)90026-X

Kahneman, D. (2003). A perspective on judgment and choice. American Psychologist, 58, 698-720. http://dx.doi.org/10.1037/0003-066X.58.9.697

Kahneman, D., Slovic, P., \& Tversky, A. (1982). Judgment under uncertainty: Heuristics and biases. Cambridge: Cambridge University Press.

Kanter, R.M. (1994). Collaborative advantage: The art of alliances. Harvard Business Review, 72, 96-109.

Klein, G. (2003). Intuition at work. New York: Random House.

Kohl, F., \& Otker, T. (1985). Sponsorship - some practical experience in Philips consumer electronics. Paper presented at ESOMAR Seminar, Milan.

Koopman, P., \& Pool, J. (1991). Organizational decision making: Models, contingencies and strategies. In J. Rasmussen, B. Brehmer \& J. Leplat (Eds.), Distributed Decision Making: Cognitive Models for Cooperative Work. New York: Wiley and Sons Ltd.

Kraak, E., \& Olivier, A. J. (1997). Sponsorship effectiveness. Paper presented at the ESOMAR seminar, Paris.

Kraus, S., Harms, R., \& Schwarz, E. (2006). Strategic planning in smaller enterprises New empirical findings. Management Research News, 29, 334-344. http://dx.doi.org/10.1108/01409170610683851

Kumar, N. (1996). The power of trust in manufacturer-retailer relationships. Harvard Business Review, 74, 92-106.

Kuzma, J.R., Shanklin, W.L., \& McCally, J. F. (1993). Number one principle for sporting events seeking corporate sponsors: Meet benefactors' objectives. Sport Marketing Quarterly, 2, 27-32.

Langley, A. (1990). Patterns in the use of formal analysis in strategic decisions. Organisational Studies, 11, 17-45. http://dx.doi.org/10.1177/017084069001100104

Lambert, R.A. (2001). Contracting theory and accounting. Journal of Accounting and Economics, 32, 3-87. http://dx.doi.org/10.1016/S0165-4101(01)00037-4

Lamminmaki, D., Guilding, C., \& Pike, R. (1996). A comparison of British and New Zealand capital budgeting practices. Pacific Accounting Review, 8, 1-29.

McBurney, D. (1994). Research methods. Pacific Grove, California: Brooks/Cole Publishers.

Mares, E.J. (1991). Strategic dilemma's in topteams. Dewenta: Kluwer Bedrijfswetenschappen. 
Masterman, G. (2007). Sponsorship for a return on investment. Oxford: ButterworthHeinemann.

Masterman, G., \& Wood, E.H. (2006). Innovative marketing communications: Strategies for the events industry. Oxford: Elsevier.

Meenaghan, T. (1991). The role of sponsoring in the marketing communications mix. International Journal of Advertising, 10, 35-47.

Merchant, K. (1981). The design of the corporate budgeting system: Influences on managerial behavior and performance. The Accounting Review, 4, 813-829.

Miller, P., Kurunmäki, L., \& O’Leary, T. (2008). Accounting, hybrids and management of risk. Accounting, Organizations and Society, 33, 942-967. http://dx.doi.org/10.1016/j.aos.2007.02.005

Mintzberg, H. D., Raisinghani, D., \& Theoret, A. (1976). The structure of "unstructured decision" processes. Administrative Science Quarterly, 21, 246-275. http://dx.doi.org/10.2307/2392045

Muller, C.C., \& Ireland, R. (2005). Intuition in strategic decision-making: Friend or foe in the fast-paced $21^{\text {st }}$ Century. The Academy of Management Executive (19932005), 19. http://dx.doi.org/10.1109/EMR.2005.26745

Neu, D. (1991). Trust contracting and the prospectus process. Accounting, Organisations and Society, 16, 243-256. http://dx.doi.org/10.1016/03613682(91)90003-W

Nunnaly, J. (1978). Psychometric theory. New York: McGraw-Hill.

Olson, E.M., Slater, S.F., \& Hult, G.T. (2005). The performance implications of fit among business strategy, marketing organization structure, and strategic behavior. Journal of Marketing, 69, 49-65. http://dx.doi.org/10.1509/jmkg.69.3.49.66362

Palmatier, R.W., Dant, R. P., \& Grewal, D. (2007). A comparative longitudinal analysis of theoretical perspectives of interorganizational relationship performance. Journal of Marketing, 71(4), 172-194. http://dx.doi.org/10.1509/jmkg.71.4.172

Pitts, B., \& Stotlar, D. (2007). Fundamentals of sport marketing (3ed.). Morgantown, WV.: Fitness Information Technologies.

Pope, N.K.L. (1996). Sponsorship and image: An investigation into the relationship between awareness of corporate sponsorship of sport and corporate image, mediated by gender and purchase decision involvement. (Unpublished doctoral dissertation), Griffith University, Brisbane.

Pope, N.K.L. (1998). Consumption values, sponsorship awareness, brand and product use. Journal of Product and Brand Management, 7, 124-136. http://dx.doi.org/10.1108/10610429810216883 
Pope, N.K.L., \& Voges, K.E. (2000). The impact of sports sponsorship activities, corporate image, and prior use on customer purchase intention. Sports Marketing Quarterly, 9, 96-102.

Ring, P.S., \& Van de Ven, A.H. (1992). Structuring cooperative relationships between organizations. Strategic Management Journal, 13, 483-498. http://dx.doi.org/10.1002/smj.4250130702

Ross, Westerfield, and Jordan (2008). Corporate finance fundamentals (8ed.). Sydney: McGraw-Hill/Irwin.

Sadler-Smith, E., Hodgkinson, G.P., \& Sinclair, M. (2008). A matter of feeling? The role of intuition in entrepreneurial decision-making and behaviour. Research on Emotion in Organizations, 4, 35-55. http://dx.doi.org/10.1016/S17469791(08)04002-9

Sandler, D.M., \& Shani, D. (1993). Sponsorship and the Olympic Games: The consumer perspective. Sport Marketing Quarterly, 2, 38-45.

Schoch, R.B. (1994). Image and attitude research to attract sponsorships - A case study of the 'Swiss League for the Protection of Nature'. Marketing and Research Today, February, 75-87.

Shank, M. (2005). Sports marketing - A strategic perspective (3ed.). Upper Saddle River, NJ: Pearson Prentice-Hall.

Schoemaker, J.H., \& Russo, J.E. (1993). A pyramid of decision approaches. California Management Review, 36, 9-31. http://dx.doi.org/10.1007/978-94-011-1372-4_4

Shapiro, S., \& Spence, M.T. (1997). Managerial intuition: A conceptual and operational framework. Business Horizons, 40, 63-68. http://dx.doi.org/10.1016/S00076813(97)90027-6

Sidhu, B. K, \& Roberts, J.H. (2008). The marketing accounting interface - lessons and limitations. Journal of Marketing Management, 24(7-8), 669-686. http://dx.doi.org/10.1362/026725708X345461

Simons, R. (1987). Accounting control systems and business strategy: An empirical analysis. Accounting, Organizations and Society, 12, 357-374. http://dx.doi.org/10.1016/0361-3682(87)90024-9

Snell, S. (1992). Control theory in strategic human resource management: The mediating effect of administrative information. The Academy of Management Journal, 35, 292-327. http://dx.doi.org/10.2307/256375

Stewart, D. (2006). Making marketing accountable: The role of standards and metrics presented at the American Marketing Association Winter Educator's Conference. St Petersburg, FL. 
Stotlar, D. (2001). Developing successful sport sponsorship plans. Morgantown, WV: Fitness Information Technologies.

Stotlar, D. (2004). Sponsorship evaluation: Moving from theory to practice. Sport Marketing Quarterly, 13, 61-64.

Sweet, J. (2002). ROI drawing closer attention from sponsors. Sport Business Journal, 27.

Tabachnick, B.G., \& Fidell, L.S. (2007). Multivariate Statistics (5th ed.). Boston: Allyn and Bacon

Thwaites, D., \& Carruthers, A. (1998). Practical applications of sponsorship theory: Empirical evidence from English club rugby. Journal of Sport Management, 12, 203-219.

Van Cauwenbergh, A., Durinck, E., Martens, R., Laveren, E., \& Bogaert, I. (1996). On the role and function of formal analysis in strategic investment decision processes: Results from an empirical study in Belgium. Management Accounting Research, 7, 169-187. http://dx.doi.org/10.1006/mare.1996.0010

Walker, O.C., \& Ruekert, R.W. (1987). Marketing's role in the implementation of business strategies: A critical review and conceptual framework. Journal of Marketing, 51, 15-33. http://dx.doi.org/10.2307/1251645

Zaheer, A., McEvily, B., \& Perrone, V. (1998). Does trust matter? Exploring the effects of interorganizational and interpersonal trust on performance. Organization Science, 9, 141-159. http://dx.doi.org/10.1287/orsc.9.2.141

Zaheer, A., \& Venkatraman, N. (1995). Relational governance as an interorganizational strategy: An empirical test of the role of trust in economic exchange. Strategic Management Journal, 19, 373-392. http://dx.doi.org/10.1002/smj.4250160504 


\section{APPENDIX A}

\section{Questionnaire items}

\section{Degree of intuition used in the sponsorship decision-making process measurement items:}

To what extent do you agree with the following statements?

\begin{tabular}{|c|c|c|c|c|c|c|c|c|}
\hline \multicolumn{7}{|c|}{ Not at all } & \multicolumn{2}{|c|}{$\begin{array}{r}\text { To a large } \\
\text { extent }\end{array}$} \\
\hline \multicolumn{9}{|c|}{ a. The manager who oversees most sponsorship decisions in your organisation } \\
\hline Int1 & is comfortable making intuitively based decisions. & 1 & 2 & 3 & 4 & 5 & 6 & 7 \\
\hline Int2 & is comfortable taking a gut feel approach in sponsorship decision-making. & 1 & 2 & 3 & 4 & 5 & 6 & 7 \\
\hline Int3 & $\begin{array}{l}\text { prefers to take an intuitive approach rather than a numbers based approach } \\
\text { in justifying a decision to sponsor. }\end{array}$ & 1 & 2 & 3 & 4 & 5 & 6 & 7 \\
\hline \multicolumn{9}{|c|}{ b. In my organisation } \\
\hline Int4 & $\begin{array}{l}\text { sponsorship proposals are accepted if, on face value, they appear to make } \\
\text { sound commercial sense. }\end{array}$ & 1 & 2 & 3 & 4 & 5 & 6 & 7 \\
\hline Int5 & $\begin{array}{l}\text { we will tend to go with a sponsorship proposal if it gives us a good 'gut } \\
\text { feel'. }\end{array}$ & 1 & 2 & 3 & 4 & 5 & 6 & 7 \\
\hline Int6 & the sponsorship decision-making process is quite intuitive. & 1 & 2 & 3 & 4 & 5 & 6 & 7 \\
\hline
\end{tabular}

Formalisation of the sponsorship decision-making process measurement items:

To what extent do you agree with the following statements relating to how decisions are made to allocate funds to sponsorship projects?

\begin{tabular}{|c|c|c|c|c|c|c|c|c|}
\hline \multirow[b]{2}{*}{ Form1 } & \multicolumn{6}{|c|}{ Not at all } & \multicolumn{2}{|c|}{$\begin{array}{r}\text { To a large } \\
\text { extent }\end{array}$} \\
\hline & $\begin{array}{l}\text { Formal analysis and justification are used in sponsorship decision-making } \\
\text { in your organisation. }\end{array}$ & 1 & 2 & 3 & 4 & 5 & 6 & 7 \\
\hline Form2 & $\begin{array}{l}\text { Documented sponsorship decision-making procedures exist in your } \\
\text { organisation. }\end{array}$ & 1 & 2 & 3 & 4 & 5 & 6 & 7 \\
\hline Form3 & $\begin{array}{l}\text { Sponsorship goals are used to reach consensus and allocate resources to } \\
\text { sponsorships. }\end{array}$ & 1 & 2 & 3 & 4 & 5 & 6 & 7 \\
\hline Form4 & $\begin{array}{l}\text { A formal checklist is used as a basis for appraising the merits of each } \\
\text { sponsorship proposal. }\end{array}$ & 1 & 2 & 3 & 4 & 5 & 6 & 7 \\
\hline Form5 & Sponsorship expenditure is a group based decision. & 1 & 2 & 3 & 4 & 5 & 6 & 7 \\
\hline Form6 & $\begin{array}{l}\text { Well-documented systems are adhered to when making sponsorship } \\
\text { decisions. }\end{array}$ & 1 & 2 & 3 & 4 & 5 & 6 & 7 \\
\hline
\end{tabular}

Importance of trust in a sponsorship relationship measurement items:

To what extent do you agree with the following statements about your organisation's approach to sponsorship?

\begin{tabular}{|c|c|c|c|c|c|c|c|c|}
\hline \multicolumn{7}{|c|}{$\begin{array}{l}\text { Strongly } \\
\text { disagree }\end{array}$} & \multicolumn{2}{|c|}{$\begin{array}{r}\begin{array}{r}\text { Strongly } \\
\text { agree }\end{array}\end{array}$} \\
\hline a. & $\begin{array}{l}\text { My organisation places great importance on trust when entering into } \\
\text { sponsorship arrangements. }\end{array}$ & 1 & 2 & 3 & 4 & 5 & 6 & 7 \\
\hline b. & $\begin{array}{l}\text { My organisation strongly prefers to only deal with organisations with which } \\
\text { we have a well-established relationship when entering into a sponsorship } \\
\text { arrangement. }\end{array}$ & 1 & 2 & 3 & 4 & 5 & 6 & 7 \\
\hline c. & $\begin{array}{l}\text { For my organisation, having a good rapport with personnel in the } \\
\text { organisation being sponsored is a key factor in deciding to enter a } \\
\text { sponsorship arrangement. }\end{array}$ & 1 & 2 & 3 & 4 & 5 & 6 & 7 \\
\hline
\end{tabular}

